\title{
Procalcitonin: A Key Marker in Children with Urinary Tract Infection
}

\author{
Sandrine Leroy ${ }^{1,2}$ and Alain Gervaix ${ }^{3}$ \\ ${ }^{1}$ Centre for Statistics in Medicine, Wolfson College Annexe, University of Oxford, Linton Road, Oxford OX2 6UD, UK \\ ${ }^{2}$ Pasteur Institute, 75015 Paris, France \\ ${ }^{3}$ Department of Pediatrics, University Hospital of Geneva, 1211 Geneva, Switzerland
}

Correspondence should be addressed to Sandrine Leroy, sandrine.leroy@csm.ox.ac.uk

Received 1 November 2010; Revised 20 December 2010; Accepted 21 December 2010

Academic Editor: Ming Hsien Wang

Copyright ( $) 2011$ S. Leroy and A. Gervaix. This is an open access article distributed under the Creative Commons Attribution License, which permits unrestricted use, distribution, and reproduction in any medium, provided the original work is properly cited.

Urinary tract infections (UTIs) are the most common source of bacterial infections among young febrile children. Accurate diagnosis of acute pyelonephritis (APN) and vesicoureteral reflux (VUR) is important because of their association with renal scarring, leading in the cases to long-term complications. However, the gold standard examinations for both are either DMSA scan (for APN and scar) or cystography (for VUR) and present limitations (feasibility, pain, cost, etc.). Procalcitonin, a reliable marker of bacterial infections, was demonstrated to be a good predictor of both renal parenchymal involvement in the acute phase and late renal scars. Furthermore, it was also found to be associated with high-grade VUR and was the key tool of a clinical decision rule to predict high-grade VUR in children with a first UTI. Therefore, procalcitonin may certainly be found playing a role in the complex and still debated picture of which examination should be performed after UTI in children.

\section{Introduction}

Urinary tract infections (UTIs) are the most common source of bacterial infections among young febrile children [1]; 7\% of girls and 2\% of boys will have a UTI before 6 years of age [2]. The nonspecific nature of symptoms among febrile infants and young children renders the clinical differentiation of upper and lower UTI difficult. However, accurate diagnosis and early treatment of acute pyelonephritis are important because of its association with renal scarring [3]. Thus, the belief that future complications related to renal scarring such as hypertension, pre-eclampsia, poor renal growth, and end-stage renal failure can occur have been a major driving force in the impetus to first make a prompt and high-quality diagnosis of UTI and then investigate the first occurrence of UTI for vesicoureteral reflux (VUR) and other urinary tract abnormalities [4, 5]. But which examination should be performed and in which order is a strongly debated topic for both early UTI diagnosis examinations and later investigations [6-8]. Among those, procalcitonin (PCT) should find a place in the diagnostic strategy for UTI. PCT, a 116-amino acid propeptide of calcitonin without hormonal activity, is a reliable marker of bacterial infections $[9,10]$. In this paper, we aimed to review the clinical interest of PCT, and its place in the complex picture of which examination to prescribe in children with UTI.

\section{Procalcitonin}

PCT is the prehormone of calcitonin, which is normally secreted by the $\mathrm{C}$ cells of the thyroid in response to hypercalcemia. Under normal conditions, negligible serum PCT concentrations are detected [11], but PCT serum level rises during bacterial infections, as first demonstrated by Assicot et al. [9]. The mechanism proposed for PCT production after inflammation and its role are still not yet completely elucidated. It is believed that PCT is produced by the liver and peripheral blood mononuclear cells, modulated by lipopolysaccharides and sepsis-related cytokines. Microbial infections induce a ubiquitous increase in CALC1 gene expression and a subsequent release of calcitonin 
precursors [12]. In bacterial infections, PCT increases from concentrations in the picogram range (below the detection level of current PCT assays) to plasma concentrations ranging from 1 to $1000 \mathrm{ng} / \mathrm{mL}$. This increase often correlates with the severity of diseases and with mortality [9]. Moreover, PCT is very specific of bacterial infection and helps to distinguish between viral and bacterial infections which is particularly useful in children [10]. Increase in PCT occurs more rapidly than increase in CRP. PCT can be detected in the plasma 2 hours after the injection of endotoxins. Within 6-8 hours, PCT concentrations rise and a plateau is reached after approximately 12 hours. PCT decreases to its normal values after 2-3 days. This rapid and specific induction of PCT after an adequate stimulus, and the high and reliable production of PCT in patients with bacterial infections or sepsis, suggests a pathophysiological function of PCT in the acute immune response, even though it is not clear whether PCT is a cytokine, a hormone, or an acute-phase protein since it has characteristics of all these mediators.

PCT can be measured with a quantitative immunoluminometric assay (LUMItest PCT, progressively replaced by PCT sensitive KRYPTOR, both from Brahms Diagnostica, Berlin, Germany) in 2 hours, with a maximum interassay variation of approximately $0.3 \mathrm{ng} / \mathrm{mL}$. A rapid semiquantitative chromatographic test (Brahms PCT-Q, Brahms Diagnostica) can be used at the bedside and gives an indication of PCT concentration (in bands of $<0.5 \mathrm{ng} / \mathrm{mL}, 0.5-2 \mathrm{ng} / \mathrm{mL}$, $2-10 \mathrm{ng} / \mathrm{mL}$, and $>10 \mathrm{ng} / \mathrm{mL}$ ) in $30 \mathrm{~min}$.

PCT has been used for one and a half decades in a number of hospitals as a clinical routine parameter for the diagnosis of sepsis [13] since its first demonstration by Assicot et al. [9]. There are several reasons for the clinical success of PCT. Plasma concentrations respond rather specifically to bacterial infection, and PCT has been demonstrated to be a better or at least of equal value for diagnosis of sepsis when compared with markers like $\mathrm{CPR}$, lactate, proinflammatory cytokines, leukocytosis, and fever [10]. Not only diagnosis of sepsis but also diagnosis of specific infection can be improved by measuring PCT, as demonstrated by the meta-analysis comparing PCT and CRP in patients with bacterial versus viral or nonbacterial infections [10]. Moreover, PCT is helpful in monitoring the activity for the systemic inflammatory response, the success of therapy, and in estimating prognosis $[10,13]$.

\section{PCT and Acute Pyelonephritis}

The nonspecific nature of symptoms of acute pyelonephritis (APN) among febrile children renders the diagnosis of upper UTI difficult, whereas an accurate, quick, and readily available diagnostic test for an early and high-quality diagnosis of APN is of value. Renal scintigraphy with Tc99m dimercaptosuccinic acid (DMSA) is considered as the gold standard for the demonstration of renal parenchymal involvement in children with a UTI [14], once the diagnosis of bacterial UTI remains indisputably based on the result of urine culture $[4,5]$. However, not only does this modality entails irradiation, requires special equipment and facilities for its completion that are not easily available in a number of hospitals, but it is also expensive. Hence, a biological marker that would assist the clinician into predicting renal parenchymal involvement in a child with UTI would be valuable. Several teams conducted cohort studies to investigate the diagnostic accuracy of PCT for APN (Table 1) [15-27]. Most of authors concluded that PCT has a good diagnostic accuracy and an interesting clinical value for APN, with a sensitivity and a specificity ranging from 70 to $100 \%$ and 70 to $97 \%$, respectively, across studies and thresholds [15-19, 21-27]. However, the Belgium team found lower sensitivity and specificity (68\% and $23 \%$, resp.) with no obvious difference regarding the cutoff or the population's characteristics [20]. Mantadakis et al. summarised most of these studies in a systematic review and meta-analysis (10 studies, $n=627$ ) and demonstrated that the pooled diagnostic odds ratio (OR) measuring the association between DMSA-proven APN and PCT was 14.3 (95\% confidence interval-CI, 4.7-42.2), after having pooled results from studies using close PCT threshold (0.5 and $0.6 \mathrm{ng} / \mathrm{mL}$ ) [28]. However, this pooled result may be questionable regarding the strong heterogeneity it comes with $(Q$-test: $P<.001$; $\left.I^{2}=80 \%\right)$. Interestingly, an updated meta-analysis validated these results using individual patients data (17 studies, 13 centres, $n=1011$ ); the relationship between APN and PCT $\geq 0.5 \mathrm{ng} / \mathrm{mL}$ after adjustment on all cofactors of interest was significant (adjusted OR $=6.4 ; 95 \% \mathrm{CI}, 4.6-8.8$ ), with $74 \%$ (95\% CI, 71-78) sensitivity and 71\% (95\% CI, 66-75) specificity [29]. This is encouraging in building algorithms to identify children at high risk of acute pyelonephritis (i.e., with proven renal parenchymal involvement) once the diagnosis of UTI is made by urine culture in order to limit early DMSA scan to them. However, pieces of evidence and research are still needed before clinicians can use PCT as a daily and perfectly defined tool.

\section{PCT and Renal Scarring}

Beyond making a proper, high-quality, and prompt diagnosis of APN, the prediction of late renal scars is also of interest, as it may be related to future complications, such as hypertension, pre-eclampsia, poor renal growth, and endstage renal failure [30]. Pediatricians aim to early identifying children with renal scars after UTI in order to propose a more specific followup to prevent the impairment of the renal function. The gold standard examination for scar is DMSA scan 6 to 12 months after UTI, and the same problems of irradiation, availability, and cost make it not so often performed. The PCT serum level at the time of UTI was then studied by several authors as a potential predictor for late renal scars (Table 2) [16-18, 20, 22, 26, 27, 31]. Zaffanello et al. reviewed these results in a nonsystematic review and concluded to conflicting findings [32]. However, a meta-analysis of the individual patient data $(n=361)$ clarified the discrepancies finding a significant relationship between renal scars and a PCT $\geq 0.5 \mathrm{ng} / \mathrm{mL}(\mathrm{aOR}=2.1$; 95\% CI, 1.4-3.9) when pooling all the data together [29]. High PCT offered a 79\% (95\% CI, 71-86) sensitivity and 


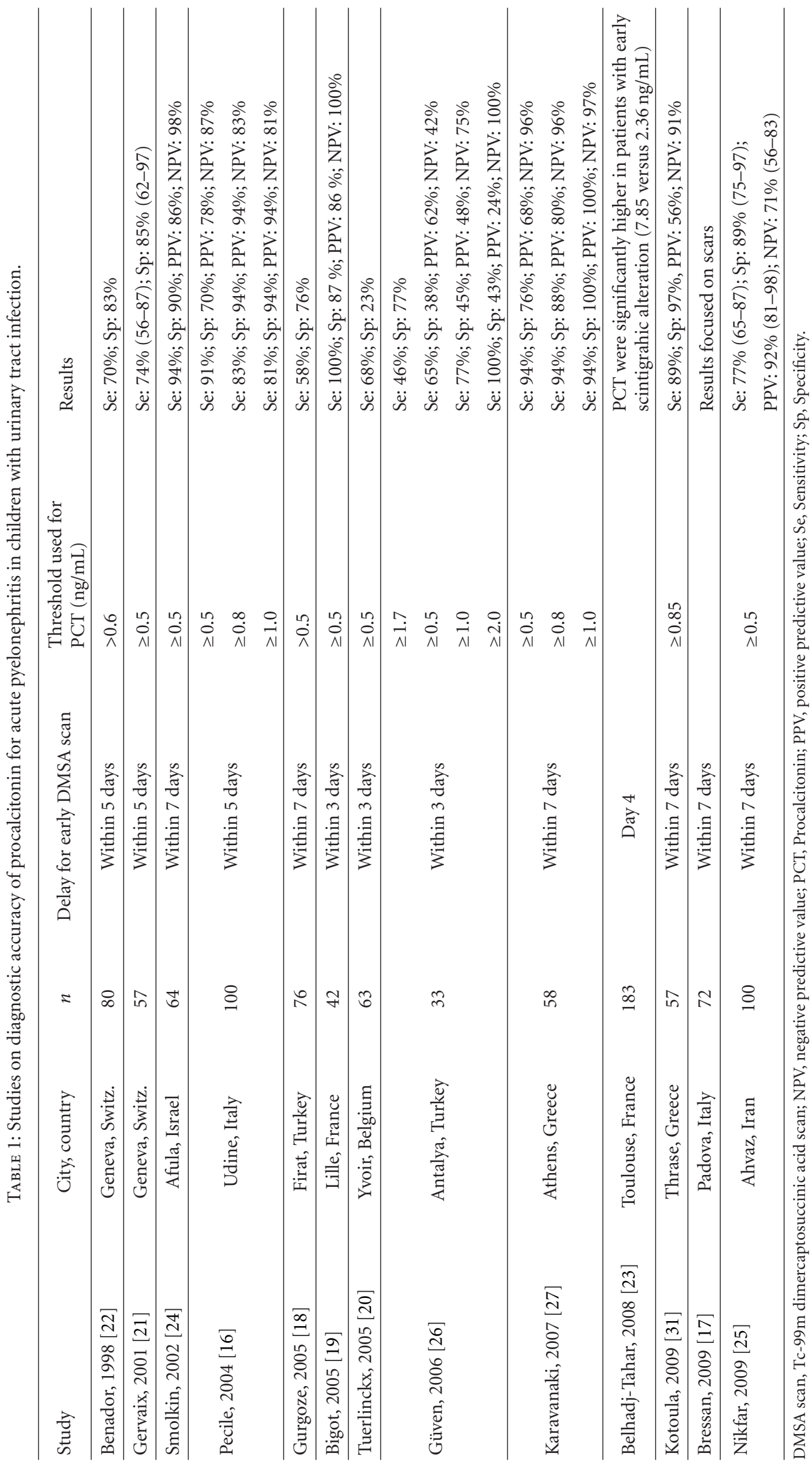




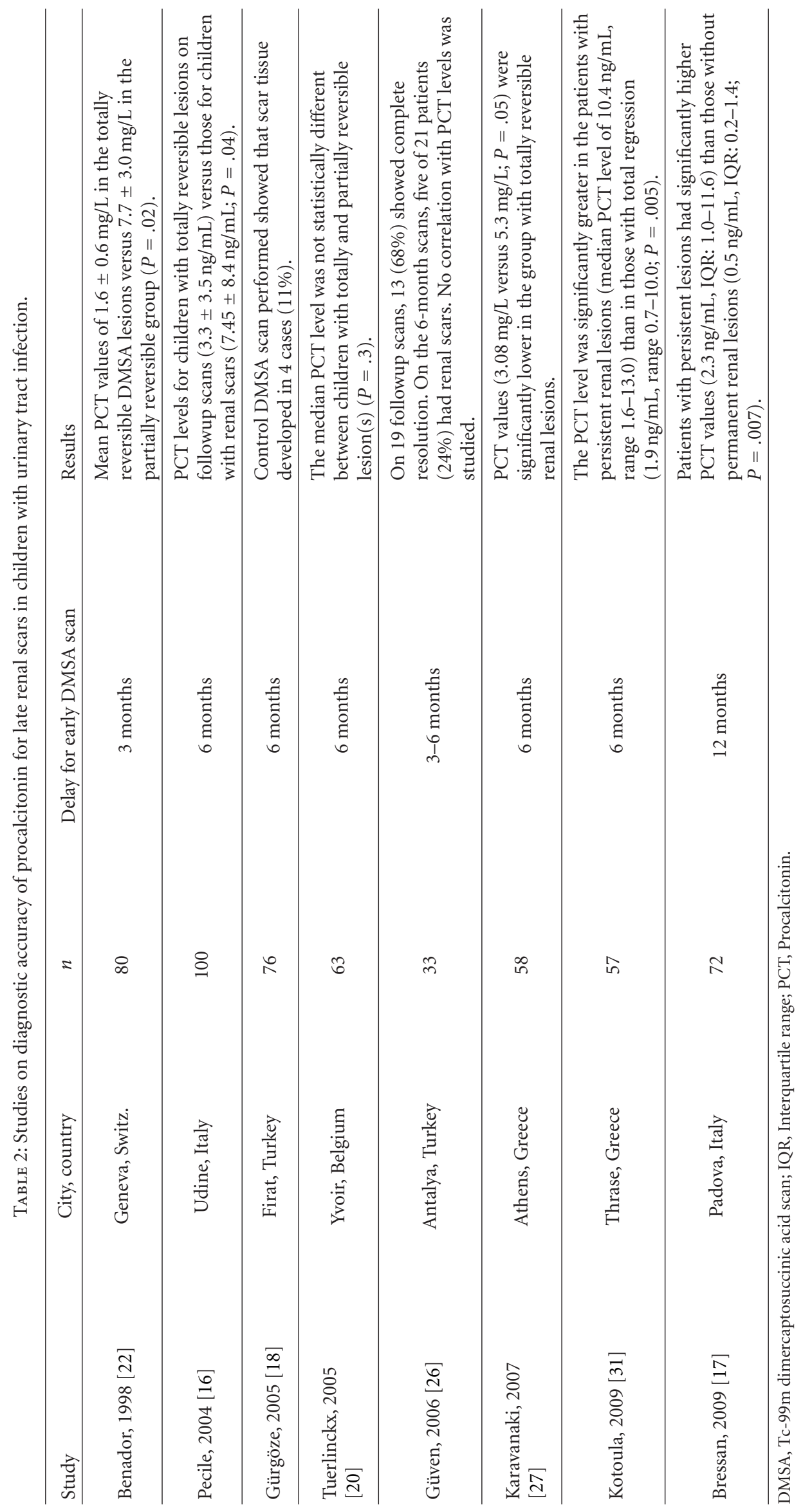


TABLE 3: Studies on prediction accuracy of procalcitonin for vesicoureteral reflux in children with urinary tract infection.

\begin{tabular}{|c|c|c|c|c|c|c|c|c|}
\hline \multirow{2}{*}{ Study } & \multirow{2}{*}{ City, country } & \multirow[t]{2}{*}{$n$} & \multicolumn{3}{|c|}{ All-grade VUR } & \multicolumn{3}{|c|}{ High-grade VUR } \\
\hline & & & $\mathrm{aOR}^{*}$ & Sensitivity & Specificity & OR & Sensitivity & Specificity \\
\hline Prevur II study [34] & Paris, France & 136 & $4.9(1.7-14.0)$ & $85 \%(70-94)$ & $44 \%(35-54)$ & $8.7(1.2-382)$ & $92 \%(65-99)$ & $44 \%(35-54)$ \\
\hline Prevur III study [36] & Multicentre & 398 & $2.5(1.4-4.4)$ & $75 \%(66-83)$ & $43 \%(37-48)$ & $24.7(1.5-415)^{\dagger}$ & $100 \%(81-100)$ & $43 \%(37-48)$ \\
\hline Prevur IIIb study [37] & Multicentre & 526 & - & - & - & $2.5(1.1-5.4)^{*}$ & $83 \%(71-91)$ & $43 \%(38-47)$ \\
\hline Prevur V study** [38] & Multicentre & 494 & - & - & - & $5.2(2.4-11.3)$ & $86 \%(74-93)$ & $47 \%(42-51)$ \\
\hline
\end{tabular}

*aOR: Adjustment on usual cofactors of interest: age, gender, family history, renal ultrasonography results, and urine collection techniques (in Prevur III study [36]), or early DMSA scan results (in Prevur IIIb study [37]).

** This study built a rule combining PCT and ureteral dilation on renal ultrasonography and studied its prediction accuracy for high-grade VUR.

${ }^{\dagger}$ Relationship between high PCT and grade 4 and 5 VUR.

All results were given with the $95 \%$ confidence interval in brackets.

Abbreviations: aOR, adjusted odds ratio; VUR, vesicoureteral reflux.

a $41 \%(95 \%$ CI, 34-48) specificity [29]. Before clinical use of PCT to identify children at high risk of renal scarring after UTI and selectively perform late DMSA-scan, validation studies and threshold analyses are needed to derive an evidence-based clinical decision rule.

\section{PCT and VUR}

PCT has been demonstrated to be correlated to both APN $[28,29]$ and late renal scars [29] on one hand, and on another hand VUR is thought to be related to a higher risk of APN and late renal scar [33]. PCT would thus be of interest to also predict VUR in children with UTI and could find a place in the investigation strategy. A first singlecentre study demonstrated a significant relationship between both all-grade and high-grade VUR and a PCT $\geq 0.5 \mathrm{ng} / \mathrm{mL}$ $(\mathrm{aOR}=4.9 ; 95 \%$ CI, 1.7-14.0-Table 3) [34]. High PCT sensitivities were $85 \%(95 \% \mathrm{CI}, 70-94)$ and $92 \%(95 \%$ CI, 65-99) for all-grade and high-grade reflux, respectively, with $44 \%$ specificity (95\% CI, 35-54) [34]. However, a strong controversy was raised regarding the urine collection techniques used (sterile bags), suggesting that this might have overestimated results [35]. These results were confirmed in two multicentre studies, adjusting the relationship between VUR and PCT on either urine collection techniques and early DMSA scan results $[36,37]$. Complex relationships between UTI, renal parenchymal involvement, and VUR may happen, and one can argue that PCT may only reflect the presence of renal parenchymal involvement during UTI, and by the way identify children with VUR as VUR is known as a risk factor for acute pyelonephritis and renal scarring. However, interestingly, the second European validation we performed demonstrated that, in children with a proven acute pyelonephritis, PCT is significantly higher in children with high-grade VUR $(\geq 3)$ than in those with low-grade or no VUR $(1.5 \mathrm{ng} / \mathrm{mL}$, interquartile range: $0.5-4.0$ versus median $4.0 \mathrm{ng} / \mathrm{mL}$, inter-quartile range: $1.5-7.0$, resp.; $P<$ .001). This definitively confirmed that PCT is a reasonable predictor for VUR. As recent publications demonstrated the absence of benefit for treating low-grade VUR, the target was then more focused on the early identification of children with only high-grade VUR. Finally, PCT was combined with renal ultrasonography findings, in order to take into account that clinicians believe in the high accuracy of ultrasonography, and a clinical decision rule was derived and internally validated [38]. Based on indirect relationships between VUR, scar and PCT, and statistical work, we ended up with a clinical tool combining PCT with renal ultrasonography that may be useful for clinicians to predict high-grade VUR in children with UTI and then selectively prescribe them a cystography. The clinical decision rule proposed in its current form that, for children aged 1 month to 4 years with a first febrile UTI, cystography should be performed in cases with ureteral dilation (i.e., ureter visible whatever its dilation) and a serum PCT level $\geq 0.17 \mathrm{ng} / \mathrm{mL}$, or without ureteral dilatation (i.e., ureter not visible) when the serum PCT level $\geq 0.63 \mathrm{ng} / \mathrm{mL}$. The rule had a sensitivity of $86 \%$ (95\% CI, 74-93) with a specificity of $47 \%$ (95\% CI, $42-51$ ). The introduction of a renal ultrasonography criterion in the decision rule may be arguable, as the diagnostic accuracy of renal US for VUR is debated, with conflicting results in literature [39]. However, this decision was made based on the strong beliefs of pediatricians that renal US predicts well VUR in order to derive a potentially well-accepted rule, and the ultrasonographic criterion with the higher diagnostic accuracy for VUR was chosen [40]. However, it needs an external validation and a measure of its clinical impact, as recommended in the standards for building such tools $[41,42]$ before its daily and safe use in clinical practice.

\section{Conclusion}

PCT, a reliable marker of bacterial infections, would find a place in the complex and still debated picture of which examination should be performed after UTI in children. Indeed, PCT demonstrated a reasonable diagnostic accuracy for both APN and renal scarring and has been proposed as a key tool for a clinical decision rule to predict high-grade VUR. However, more research is warranted to understand more in depth the physiopathologic mechanisms of PCT in bacterial infection and especially UTI on one hand, and validations, threshold analyses, and impact studies are required before daily and safe use of PCT on another hand. Moreover, the exact place of this biomarker probably would 
need to be refined when pediatrics societies would agree on a diagram of the order and timing of investigations after UTI, but PCT may be certainly found playing a role.

\section{Abbreviations}

APN: Acute pyelonephritis

OR: Odd Ratio

PCT: Procalcitonin

UTI: Urinary tract infection

VUR: Vesicoureteral reflux.

\section{Acknowledgments}

The authors gratefully thank P. Karanja (Centre for Statistics in Medicine, Oxford, UK) for helpful comments on the paper, and Professors M. Chalumeau and D. Gendrel (SaintVincent-de-Paul hospital, Paris, France) of the coordinating centre of Prevur project. Dr. S. Leroy was funded by grants from Bettencourt Foundation and the "Chancellerie des Universités de Paris.”

\section{References}

[1] N. Shaikh, N. E. Morone, J. E. Bost, and M. H. Farrell, "Prevalence of urinary tract infection in childhood: a metaanalysis," Pediatric Infectious Disease Journal, vol. 27, no. 4, pp. 302-308, 2008.

[2] S. Mårild and U. Jodal, "Incidence rate of first-time symptomatic urinary tract infection in children under 6 years of age," Acta Paediatrica, vol. 87, no. 5, pp. 549-552, 1998.

[3] S. J. Vernon, M. G. Coulthard, H. J. Lambert, M. J. Keir, and J. N. S. Matthews, "New renal scarring in children who at age 3 and 4 years had had normal scans with dimercaptosuccinic acid: follow up study," British Medical Journal, vol. 315, no. 7113, pp. 905-908, 1997.

[4] S. M. Downs, "Technical report: urinary tract infections in febrile infants and young children. The Urinary Tract Subcommittee of the American Academy of Pediatrics Committee on Quality Improvement," Pediatrics, vol. 103, no. 4, p. e54, 1999.

[5] Committee on Quality Improvement, Subcommittee on Urinary Tract Infection, "Practice parameter: the diagnosis, treatment, and evaluation of the initial urinary tract infection in febrile infants and young children," Pediatrics, vol. 103, no. 4, pp. 843-852, 1999.

[6] M. G. Coulthard, "NICE on childhood UTI: nasty processes produce nasty guidelines," BMJ, vol. 335 , no. 7618 , pp. 463 464, 2007.

[7] M. G. Coulthard, "Is reflux nephropathy preventable, and will the NICE childhood UTI guidelines help?" Archives of Disease in Childhood, vol. 93, no. 3, pp. 196-199, 2008.

[8] R. Mori, M. Lakhanpaul, and K. Verrier-Jones, "Diagnosis and management of urinary tract infection in children: summary of NICE guidance," British Medical Journal, vol. 335, no. 7616, pp. 395-397, 2007.

[9] M. Assicot, D. Gendrel, H. Carsin, J. Raymond, J. Guilbaud, and C. Bohuon, "High serum procalcitonin concentrations in patients with sepsis and infection," Lancet, vol. 341, no. 8844, pp. 515-518, 1993.

[10] L. Simon, F. Gauvin, D. K. Amre, P. Saint-Louis, and J. Lacroix, "Serum procalcitonin and C-reactive protein levels as markers of bacterial infection: a systematic review and meta-analysis," Clinical Infectious Diseases, vol. 39, no. 2, pp. 206-217, 2004.

[11] J. Whicher, J. Bienvenu, and G. Monneret, "Procalcitonin as an acute phase marker," Annals of Clinical Biochemistry, vol. 38, no. 5, pp. 483-493, 2001.

[12] B. Müller, J. C. White, E. S. Nylén, R. H. Snider, K. L. Becker, and J. F. Habener, "Ubiquitous expression of the calcitoninI gene in multiple tissues in response to sepsis," Journal of Clinical Endocrinology and Metabolism, vol. 86, no. 1, pp. 396404, 2001.

[13] M. Meisner, "Biomarkers of sepsis: clinically useful?" Current Opinion in Critical Care, vol. 11, no. 5, pp. 473-480, 2005.

[14] M. P. Lavocat, D. Granjon, D. Allard, C. Gay, M. T. Freycon, and F. Dubois, "Imaging of pyelonephritis," Pediatric Radiology, vol. 27, no. 2, pp. 159-165, 1997.

[15] A. Kotoula, S. Gardikis, A. Tsalkidis et al., "Procalcitonin for the early prediction of renal parenchymal involvement in children with UTI: preliminary results," International Urology and Nephrology, vol. 41, no. 2, pp. 393-399, 2009.

[16] P. Pecile, E. Miorin, C. Romanello et al., "Procalcitonin: a marker of severity of acute pyelonephritis among children," Pediatrics, vol. 114, no. 2, pp. e249-e254, 2004.

[17] S. Bressan, B. Andreola, P. Zucchetta et al., "Procalcitonin as a predictor of renal scarring in infants and young children," Pediatric Nephrology, vol. 24, no. 6, pp. 1199-1204, 2009.

[18] M. K. Gürgöze, S. Akarsu, E. Yilmaz et al., "Proinflammatory cytokines and procalcitonin in children with acute pyelonephritis," Pediatric Nephrology, vol. 20, no. 10, pp. 1445-1448, 2005.

[19] S. Bigot, P. Leblond, C. Foucher, V. Hue, M. D'Herbomez, and M. Foulard, "Usefulness of procalcitonin for the diagnosis of acute pyelonephritis in children," Archives de Pediatrie, vol. 12, no. 7, pp. 1075-1080, 2005.

[20] D. Tuerlinckx, T. Vander Borght, Y. Glupczynski et al., "Is procalcitonin a good marker of renal lesion in febrile urinary tract infection?" European Journal of Pediatrics, vol. 164, no. 10, pp. 651-652, 2005.

[21] A. Gervaix, A. Galetto-Lacour, T. Gueron et al., "Usefulness of procalcitonin and C-reactive protein rapid tests for the management of children with urinary tract infection," Pediatric Infectious Disease Journal, vol. 20, no. 5, pp. 507-511, 2001.

[22] N. Benador, C. A. Siegrist, D. Gendrel et al., "Procalcitonin is a marker of severity of renal lesions in pyelonephritis," Pediatrics, vol. 102, no. 6, pp. 1422-1425, 1998.

[23] H. Belhadj-Tahar, Y. Coulais, M. Tafani, and F. Bouissou, "Procalcitonin implication in renal cell apoptosis induced by acute pyelonephritis in children," Infection and Drug Resistance, vol. 1, pp. 17-20, 2008.

[24] V. Smolkin, A. Koren, R. Raz, R. Colodner, W. Sakran, and R. Halevy, "Procalcitonin as a marker of acute pyelonephritis in infants and children," Pediatric Nephrology, vol. 17, no. 6, pp. 409-412, 2002.

[25] R. Nikfar, G. Khotaee, N. Ataee, and S. Shams, "Usefulness of procalcitonin rapid test for the diagnosis of acute pyelonephritis in children in the emergency department," Pediatrics International, vol. 52, no. 2, pp. 196-198, 2010.

[26] A. G. Güven, H. Z. Kazdal, M. Koyun et al., "Accurate diagnosis of acute pyelonephritis: how helpful is procalcitonin?" Nuclear Medicine Communications, vol. 27, no. 9, pp. 715-721, 2006.

[27] K. Karavanaki, F. A. Haliotis, M. Sourani et al., "DMSA scintigraphy in febrile urinary tract infections could be omitted in children with low procalcitonin levels," Infectious Diseases in Clinical Practice, vol. 15, no. 6, pp. 377-381, 2007. 
[28] E. Mantadakis, E. Plessa, E. K. Vouloumanou, D. E. Karageorgopoulos, A. Chatzimichael, and M. E. Falagas, "Serum procalcitonin for prediction of renal parenchymal involvement in children with urinary tract infections: a meta-analysis of prospective clinical studies," The Journal of Pediatrics, vol. 155, no. 6, pp. 875-881.e1, 2009.

[29] S. Leroy, A. Fernandez-Lopez, R. Nifkar et al., Predictive ability of Procalcitonin for acute pyelonephrtitis and late renal scars in children with urinary tract infection in children: systematic review and meta-analysis on individual patient data, International Pediatrics Nephrology Association, New York, NY, USA, 2010, Pediatric Nephrology.

[30] G. Williams, J. T. Fletcher, S. I. Alexander, and J. C. Craig, "Vesicoureteral reflux," Journal of the American Society of Nephrology, vol. 19, no. 5, pp. 847-862, 2008.

[31] A. Kotoula, S. Gardikis, A. Tsalkidis et al., "Comparative efficacies of procalcitonin and conventional inflammatory markers for prediction of renal parenchymal inflammation in pediatric first urinary tract infection," Urology, vol. 73, no. 4, pp. 782-786, 2009.

[32] M. Zaffanello, M. Brugnara, M. Franchini, and V. Fanos, "Is serum procalcitonin able to predict long-term kidney morbidity from urinary tract infections in children?" Clinical Chemistry and Laboratory Medicine, vol. 46, no. 10, pp. 13581363, 2008.

[33] A. Hoberman, M. Charron, R. W. Hickey, M. Baskin, D. H. Kearney, and E. R. Wald, "Imaging studies after a first febrile urinary tract infection in young children," New England Journal of Medicine, vol. 348, no. 3, pp. 195-202, 2003.

[34] S. Leroy, C. Adamsbaum, E. Marc et al., "Procalcitonin as a predictor of vesicoureteral reflux in children with a first febrile urinary tract infection," Pediatrics, vol. 115, no. 6, pp. e706e709, 2005.

[35] I. Chevalier and M. Gauthier, "Procalcitonin and vesicoureteral reflux in children with urinary tract infection," Pediatrics, vol. 116, no. 5, pp. 1261-1262, 2005.

[36] S. Leroy, C. Romanello, A. Galetto-Lacour et al., "Procalcitonin to reduce the number of unnecessary cystographies in children with a urinary tract infection: a European validation study," Journal of Pediatrics, vol. 150, no. 1, pp. 89-95, 2007.

[37] S. Leroy, C. Romanello, A. Galetto-Lacour et al., Is procalcitonin a predictor for high-grade VUR in children even when considering DMSA-proven acute pyelonephritis? A metaanalysis of individual patient data, European Society of Pediatric Nephrology, Lyon, France, 2008.

[38] S. Leroy, C. Romanello, V. Smolkin et al., Prediction of highgrade vesicoureteral reflux after a first urinary tract infection in children: construction and internal validation of a clinical decision rule, International Pediatric Nephrology Association, New York, NY, US, 2010.

[39] P. Whiting, M. Westwood, L. Bojke et al., "Clinical effectiveness and cost-effectiveness of tests for the diagnosis and investigtion of urinary tract infection in children: a systematic review and economic model," Health Technology Assessment, vol. 10, no. 36, pp. 1-154, 2006.

[40] S. Leroy, S. Vantalon, A. Larakeb, H. Ducou-Le-Pointe, and A. Bensman, "Vesicoureteral reflux in children with urinary tract infection: comparison of diagnostic accuracy of renal US criteria," Radiology, vol. 255, no. 3, pp. 890-898, 2010.

[41] A. Laupacis, N. Sekar, and I. G. Stiell, "Clinical prediction rules: a review and suggested modifications of methodological standards," Journal of the American Medical Association, vol. 277, no. 6, pp. 488-494, 1997.
[42] T. G. McGinn, G. H. Guyatt, P. C. Wyer, C. D. Naylor, I. G. Stiell, and W. S. Richardson, "Users' guides to the medical literature XXII: how to use articles about clinical decision rules," Journal of the American Medical Association, vol. 284, no. 1, pp. 79-84, 2000. 


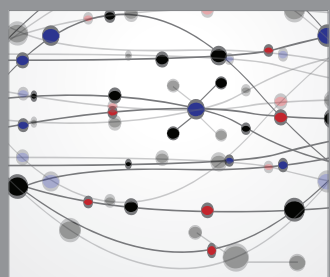

The Scientific World Journal
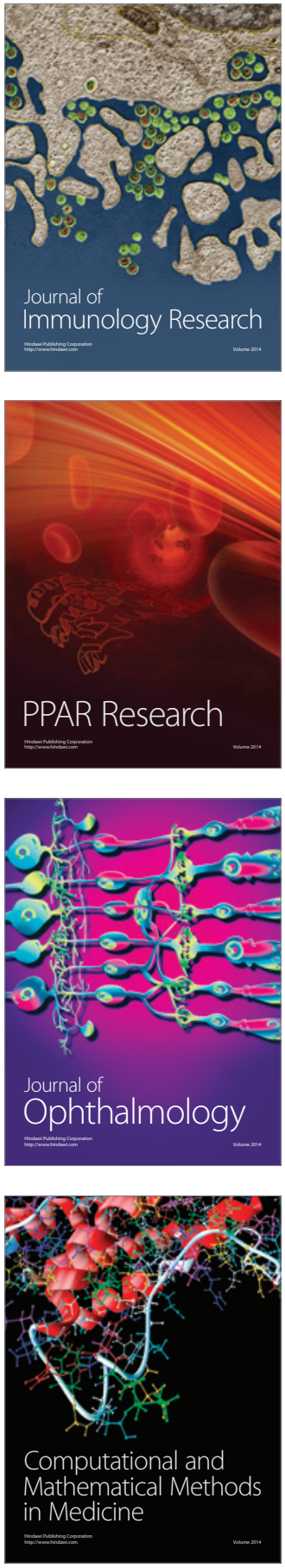

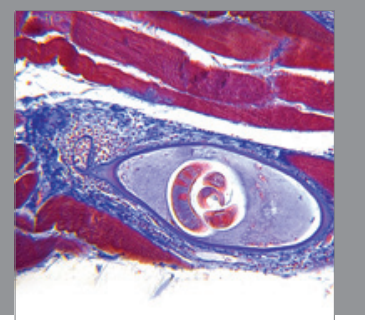

Gastroenterology

Research and Practice
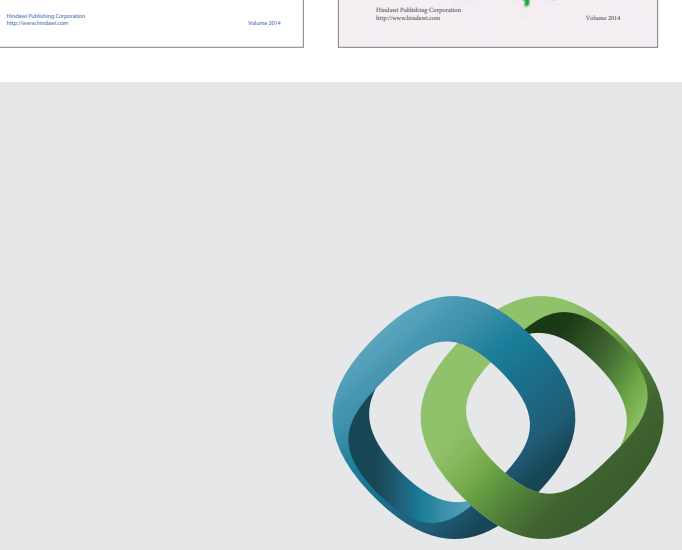

\section{Hindawi}

Submit your manuscripts at

http://www.hindawi.com
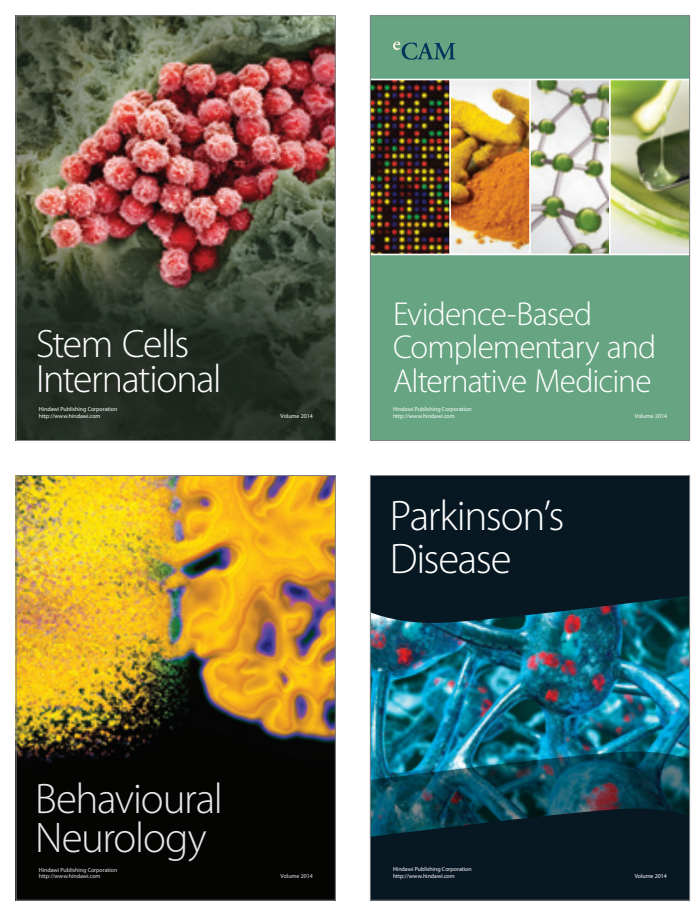

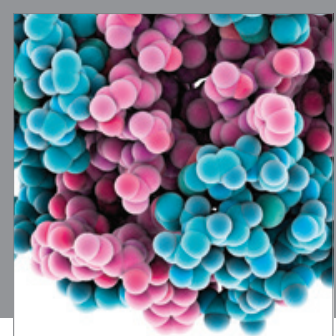

Journal of
Diabetes Research

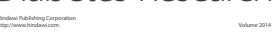

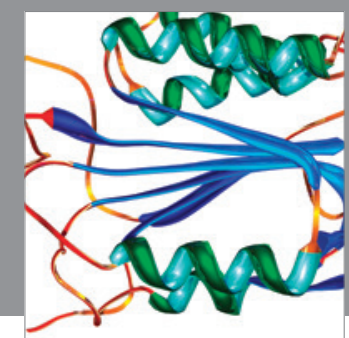

Disease Markers
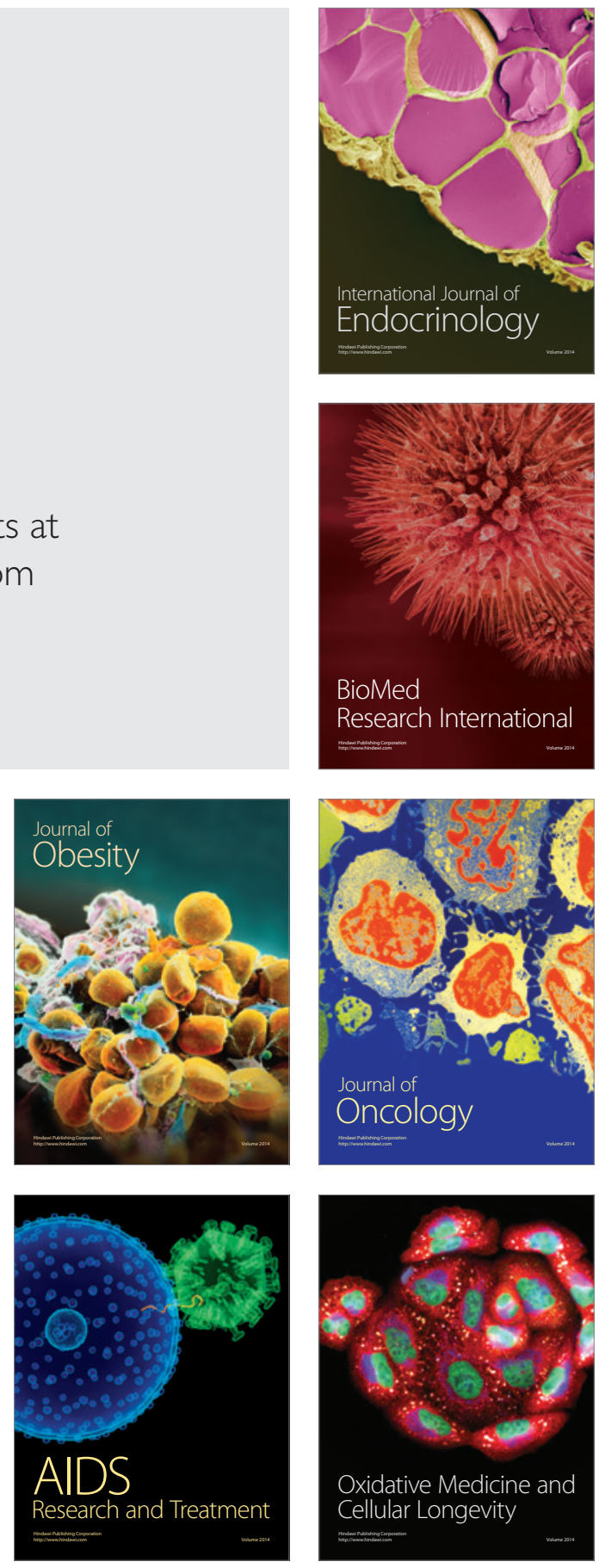